\title{
Comparative Study of Fentanyl vs Dexmedetomidine as Adjuvants to Intrathecal Bupivacaine in Cesarean Section: A Randomized, Double-Blind Clinical Trial
}

This article was published in the following Dove Press journal:

Journal of Pain Research

\author{
Fatemeh Khosravi (iD ${ }^{1,2}$ \\ Mehdi Sharifi ${ }^{\prime}$ \\ Hashem Jarineshin (D)' \\ 'Anesthesiology, Critical Care and Pain \\ Management Research Center, \\ Hormozgan University of Medical \\ Sciences, Bandar Abbas, Iran; \\ ${ }^{2}$ Department of Physiology, Faculty of \\ Medicine, Hormozgan University of \\ Medical Sciences, Bandar Abbas, Iran
}

\begin{abstract}
Purpose: Effective postoperative analgesia is essential in cesarean section. This study aimed to compare postoperative analgesia and hemodynamic changes after intrathecal use of fentanyl or dexmedetomidine combined with bupivacaine.

Patients and Methods: This study involved 110 pregnant women with ASA I and II and gestational age $\geq 37$ weeks who were candidates for elective cesarean section. They were randomly divided into two groups of 55 ; Group B-D received $10 \mathrm{mg}$ bupivacaine $(0.5 \%)+5$ $\mu \mathrm{g}$ dexmedetomidine and Group B-F received $10 \mathrm{mg}$ bupivacaine $(0.5 \%)+25 \mu \mathrm{g}$ fentanyl, intrathecally. The onset of block, duration of analgesia, the score of pain intensity, hemodynamic changes, Apgar scores, and any adverse events were evaluated. $P$-value $<0.05$ was considered statistically significant.

Results: Patients in two groups were similar in terms of demographic characteristics and ASA classification. Duration of analgesia in the B-D group was significantly longer than B-F group (428.64 \pm 73.39 vs $273.18 \pm 61.91 \mathrm{~min} ; P<0.001)$. The score of pain intensity during recovery time in the B-D group was significantly lower than that of B-F group $(0.33 \pm 0.84$ vs $0.51 \pm 0.57 \mathrm{~min} ; P=0.004)$. The onset of block was also faster in the B-D group than B-F group ( $98.27 \pm 35.95$ vs $110.45 \pm 37.69$ seconds; $P=0.036$ ). The two groups did not show significant differences in hemodynamic changes and other variables $(P>0.05)$.

Conclusion: Compared with fentanyl, it seems that adding $5 \mu \mathrm{g}$ dexmedetomidine to bupivacaine has a better effect on postoperative pain management in cesarean section under spinal anesthesia.
\end{abstract}

Keywords: spinal anesthesia, fentanyl, postoperative analgesia, dexmedetomidine

\section{Introduction}

Spinal anesthesia is still the first choice for cesarean section due to its deep sensory block as well as fewer side effects on mother and fetus. ${ }^{1,2}$ Despite many benefits of this method, it has a short duration and cannot provide sufficient postoperative analgesia. Adequate postoperative analgesia plays a crucial role in cesarean delivery because it allows better breastfeeding and caring for newborns. Nowadays, many drugs including opioids, magnesium sulfate, vasopressors, and $\alpha_{2}$-adrenergic agonists (dexmedetomidine and clonidine) have been tried extensively as an adjuvant to local anesthetic and provide some advantages not only to manage postoperative pain but also to optimize satisfaction of patients. $^{2-4}$
Correspondence: Hashem Jarineshin Anesthesiology, Critical Care and Pain Management Research Center, Hormozgan University of Medical Sciences, Bandar Abbas, Iran Fax +987633345009

Email hjarineshin@yahoo.com
Journal of Pain Research 2020:13 2475-2482 
Fentanyl is the most common short-acting opioid that is used intrathecally in combination with local anesthetics. It has synergistic effects with local anesthetics and improves the status of intraoperative and postoperative analgesia. ${ }^{3}$ It has been reported that intrathecal administration of fentanyl at the dose of 10-25 microgram can prolong the duration of postoperative analgesia for approximately 180-240 min. ${ }^{5}$ However, intrathecal opioids can cause some side effects such as itching, urinary retention, nausea and vomiting as well as respiratory depression. ${ }^{6,7}$

Dexmedetomidine (Dex), a new selective $\alpha_{2}$-agonist, is being introduced as an adjuvant to local anesthetics with significant analgesic, sympatholytic and sedative properties. $^{2,6,8}$ Compared to clonidine; Dex is approximately eight times more selective towards $\alpha_{2}$-adrenergic receptors $\left(\alpha_{2}-\mathrm{AR}\right)$, which is associated with sedative and analgesic effects in supraspinal and spinal sites and also has an antinociceptive impact on both visceral and somatic pain. More importantly, this drug does not cross the placenta significantly ( 0.77 maternal/fetal index), which confirmed its safety in cesarean delivery. ${ }^{9}$ Many reports have indicated that intrathecal administration of Dex can prolong analgesia and reduce the side effects associated with the administration of opioids. ${ }^{2,6,8,10}$ However, some studies have reported that intrathecal injection of Dex is frequently associated with some side effects, such as a decrease in heart rate and blood pressure. ${ }^{10-13}$

Since maternal and neonatal outcomes are a vital issue in cesarean section, choosing an appropriate drug to combine with local anesthetics has always been a great challenge for anesthesiologists. Hence, this study was done to compare the effect of adding dexmedetomidine vs fentanyl as an adjuvant to intrathecal bupivacaine in women who had undergone cesarean section. The primary outcome was to assess the postoperative analgesia. Our secondary outcomes were the onset of block, hemodynamic changes, and maternal complications as well as Apgar scores of neonates.

\section{Patients and Methods}

This prospective, randomized, double-blind clinical trial was conducted after approval by the Ethics Committee of Hormozgan University of Medical Sciences (Code: HUMS.REC.1394.185) and registered at with the code of IRCT20110313006044N2. Implementation of the research plan and probable side effects were explained to the patients and they were included in the study after obtaining written informed consent from all patients in accordance with the last version of the Declaration of Helsinki.

The participants included 110 parturients with gestational age $\geq 37$ weeks and ASA I and II candidates for elective cesarean section under spinal anesthesia. The patients with emergency conditions, contraindication of spinal anesthesia, history of valvular heart disease, history of allergy or sensitivity to applied drugs and patients with placenta previa as well as failed blockade or need for induction of general anesthesia were excluded.

The method of randomization of individuals into two groups was block balanced randomization using random allocation software (version 1.0.0). One hundred and twenty-six pregnant women were enrolled in our study, but 16 patients were excluded from the study (Figure 1). All 110 parturients completed the study. To conduct the double-blind clinical trial, our study drugs were prepared by the senior anesthesiologist who was not involved in further observations of the parturients and neither patients nor outcome assessor (anesthesia resident) were aware of which type of intervention they had received.

\section{Procedures and Intervention}

When patients entered the operating room, basic standard monitoring, including noninvasive blood pressure, electrocardiography and pulse oximetry were done, and initial hemodynamic parameters were measured. Before the initiation of spinal block, all patients received $10 \mathrm{~mL} / \mathrm{kg}$ Ringer solution. All 110 patients were randomly and equally divided into the following two groups:

- Group B-D received $10 \mathrm{mg}$ hyperbaric bupivacaine $0.5 \%+5 \mu \mathrm{g}$ dexmedetomidine (Precedex ${ }^{\mathrm{TM}} 200 \mu \mathrm{g} / 2$ $\mathrm{mL}$ Hospira, Inc, Lake Forest, IL, USA)

- Group B-F received $10 \mathrm{mg}$ hyperbaric bupivacaine $0.5 \%+25 \mu \mathrm{g}$ fentanyl (ROTEXMEDICA $0.5 \mathrm{mg} / 10$ $\mathrm{mL}$ Trittau, Germany)

The total volume of intrathecal injection in both groups was equal $(2.5 \mathrm{~mL})$.

Aseptic technique with $25 \mathrm{G}$ Quincke spinal needle was used for spinal anesthesia in all study subjects by an anesthesiologist in the sitting position at the level of L4-L5 intervertebral space. After observing free flow of transparent cerebrospinal fluid, the intrathecal drugs were injected. Then, patients were positioned to supine (slightly tilted to the left side) and $6 \mathrm{~L} / \mathrm{min}$ oxygen was delivered with a 


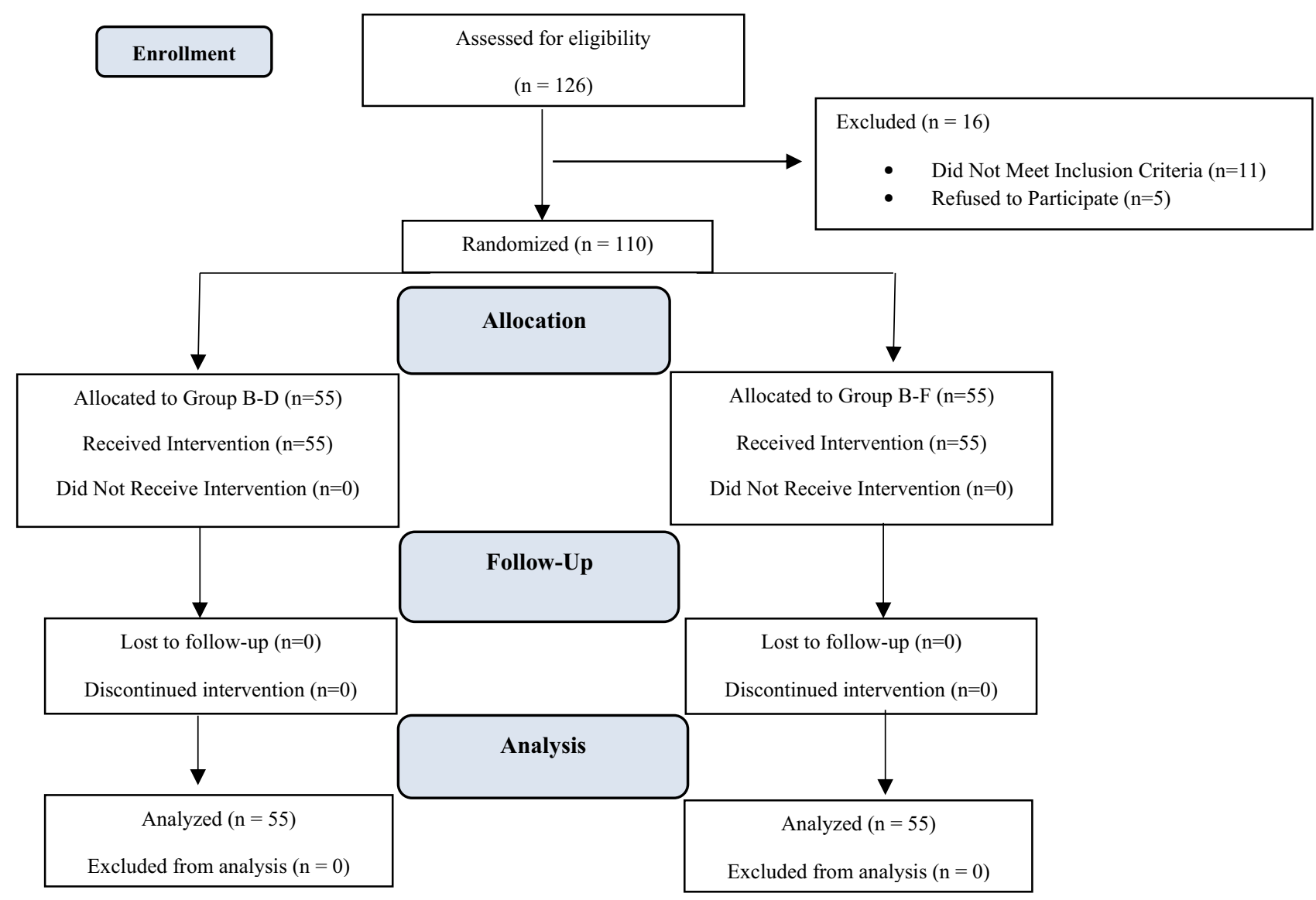

Figure I CONSORT Flow diagram.

Abbreviations: Group B-D, bupivacaine+dexmedetomidine; Group B-F, bupivacaine+fentanyl.

simple face mask. The sensory block was checked by the pinprick test, and motor block was assessed using the Bromage scale. ${ }^{14}$ When the adequate level of sensory block (T4-T6) was reached and confirmed, the surgery was allowed to begin.

\section{Measurements}

Hemodynamic monitoring including SBP and DBP, mean arterial pressure (MAP), heart rate (HR) and peripheral oxygen saturation level $(\mathrm{SpO} 2)$ were recorded intra and postoperation as follows: at the baseline values (before block); immediately after block, during the operation at $5,10,15,30$, and 60 min after spinal block, at the end of the procedure and every $10 \mathrm{~min}$ in the recovery room.

Hypotension was defined as SBP $<90 \mathrm{mmHg}$ or reduction in MAP more than $20 \%$ from baseline values and treated with $5 \mathrm{mg}$ ephedrine intravenously. Likewise, bradycardia (HR $<50$ beats/minute) was treated with $0.6 \mathrm{mg}$ of intravenous atropine. All of these episodes of hypotension and bradycardia were noted in both groups.

The onset of sensory block (time to reach T4-T6) was assessed with a pinprick test (using a blunt 25-gauge needle along the mid-clavicular line bilaterally) every two minutes and modified Bromage scale $(0=$ no motor block, $1=$ inability to flex the hip, $2=$ inability to flex the knee, and $3=$ complete motor block of limb) was used to evaluate motor block.

Patient's pain score was assessed using visual analogue scale (VAS); scored from $0-10$ (where $0=$ no pain and $10=$ the worst pain imaginable) during the recovery room (T0) and at one, three, and six hours (T1, T3, and T6) in the postoperative period. If the VAS score was more than 3, a rescue dose of pethidine $(25 \mathrm{mg})$ was administered intravenously.

Duration of analgesia was defined and noted as the time interval between block onset and the first analgesic request. The duration of surgery was recorded. The respiratory depression (respiratory rate $<10$ per minute) and the incidence of nausea, vomiting, and shivering 
were assessed and recorded during six hours after the surgery. Moreover, Apgar scores of neonates were also evaluated at one and five minutes after delivery.

\section{Sample Size}

Since the primary outcome of this study was postoperative analgesia, the sample size was calculated regarding the previous study, ${ }^{15}$ and considering $\alpha=0.05$ and power of $90 \%$, the standard deviation of postoperative analgesia based on previous study in Dex and control groups ( 0.79 and 0.59 respectively) and the mean difference of 0.44 between the two groups $\left(\mu_{1}-\mu_{2}=0.82-0.38\right)$, the sample size was calculated as 55 parturients in each group (110 in total).

\section{Statistical Analysis}

All data were analyzed by SPSS software using mean $\pm \mathrm{SD}$, Mann-Whitney $U$-test, Friedman test, Fisher's exact test, chi-squared test, ANOVA and independent sample $t$-test. The normality of quantitative data distribution was assessed by using the Kolmogorov-Smirnov test. For variables which have normal distribution, we have used independent $t$-test and for those variables which do not have normal distribution we have used nonparametric test such as Mann-Whitney $U$-test. The $P<0.05$ was considered to be statistically significant.

\section{Results}

\section{Demographic Characteristics}

Spinal anesthesia was successful in all study subjects. Demographic characteristics such as age, weight, height, ASA class were matched in two groups (Table 1).

\section{Hemodynamic Parameters}

Hemodynamic parameters (SBP, DBP, MAP, HR, and SpO2) in two groups were comparable at different time periods, and

Table I Demographic Characteristics and ASA Class

\begin{tabular}{|l|l|l|l|}
\hline Parameters & $\begin{array}{l}\text { Group B-D } \\
(\mathbf{n = 5 5 )}\end{array}$ & $\begin{array}{l}\text { Group B-F } \\
(\mathbf{n = 5 5 )}\end{array}$ & $\begin{array}{l}\text { P- } \\
\text { value }\end{array}$ \\
\hline Age (years) & $27.45 \pm 5.41$ & $29.24 \pm 4.81$ & $0.071^{\text {t }}$ \\
Weight (kg) & $71.11 \pm 12.59$ & $72.98 \pm 15.18$ & $0.483^{\text {t }}$ \\
Height (cm) & $160.53 \pm 5.62$ & $162.33 \pm 7.86$ & $0.103^{\text {t }}$ \\
ASA I/II & $43 / 12$ & $37 / 18$ & $0.254^{\#}$ \\
\hline
\end{tabular}

Notes: Values are presented as mean $\pm S D$ or numbers. Used of independent sample $t$-test, "Used of Fisher exact test. $\mathrm{P}<0.05$ was considered statistically significant.

Abbreviations: Group B-D, bupivacaine+dexmedetomidine; Group B-F, bupivacaine+fentanyl; ASA, American Society of Anesthesiologists. the findings revealed that there was no significant statistical difference between them $(P>0.05)$. Moreover, following hypotension, the mean dose of ephedrine in the B-D and B-F groups were $5.36 \pm 7.07$ and $6.82 \pm 5.25 \mathrm{mg}$, respectively. In this regard, the Mann-Whitney test showed that there was no significant difference between the two groups $(P=0.955)$. With respect to the bradycardia, the mean dose of atropine in the B-D and B-F groups were $0.10 \pm 0.26$ and $0.05 \pm 0.17 \mathrm{mg}$, respectively. According to the Mann-Whitney test, in this regard, no significant difference was seen between the two groups $(P=0.350)$.

\section{Sensory Block Evaluation}

The results of the Mann-Whitney $U$-test indicated that the onset of block in the B-D group ( $98.27 \pm 35.98$ seconds) was significantly faster than in the B-F group (110.45 \pm 37.69 seconds) $(P=0.036)$.

Considering the level of sensory block, T4 level was shown in $68(61.8 \%)$ patients, from whom $38(55.9 \%)$ and $30(44.1 \%)$ patients were in the B-D and B-F groups, respectively. Moreover, T6 level was observed in 42 (38.2\%) patients, from whom 17 (40.5\%) and 25 (59.5\%) patients were in the B-D and B-F groups, respectively. Chi-squared test revealed that there was no statistically significant difference between the two groups $(P=0.116)$.

\section{Postoperative Pain Score Evaluation}

The pain score was measured at the first hour of arrival in the recovery (T0) as well as at one, three, and six hours (T1, T3, and T6) in the postoperative period. According to the results of the Mann-Whitney $U$-test, the mean VAS scores indicated a significant reduction during recovery time in the B-D group $(P=0.004)$. However, no significant

Table 2 Evaluation of Postoperative Pain Scores (VAS) in Two Groups

\begin{tabular}{|l|l|l|l|}
\hline Time & $\begin{array}{l}\text { Group B-D } \\
(\mathbf{n = 5 5 )}\end{array}$ & $\begin{array}{l}\text { Group B-F } \\
(\mathbf{n}=55)\end{array}$ & P-value \\
\hline T0 & $0.33 \pm 0.84$ & $0.51 \pm 0.57$ & $0.004^{*}$ \\
TI & $1.91 \pm 1.41$ & $2.02 \pm 0.89$ & 0.811 \\
T3 & $4.38 \pm 1.63$ & $4.53 \pm 1.30$ & 0.371 \\
T6 & $8.67 \pm 1.67$ & $8.80 \pm 1.31$ & 0.997 \\
\hline
\end{tabular}

Notes: Values are presented as mean \pm SD. Use of Mann-Whitney U-test. $P<0.05$ was considered statistically significant. *Significant difference between two groups according to Mann-Whitney U-test at TO.

Abbreviations: Group B-D, bupivacaine+dexmedetomidine; Group B-F, bupivacaine +fentanyl; TO, at the first hour of arrival in the recovery room; TI, first hour postoperatively; T3, third hour postoperatively; T6, sixth hour postoperatively. 
difference was observed in the mean of pain intensity between the two groups at other times $(P>0.05)$ (Table 2$)$.

The mean dose of pethidine for pain relief in the postoperative period in the B-D and B-F groups was $2.73 \pm 7.87$ and $4.37 \pm 11.28 \mathrm{mg}$, respectively. In this regard, there was no significant difference between the two groups in accordance with the Mann-Whitney $U$-test $(P=0.374)$.

\section{Duration of Analgesia, Motor Block and Surgery}

In the B-D group, there was a significantly longer duration of analgesia than in the B-F group $(P<0.001)$. The mean duration of motor block in the B-D and B-F groups was $264.86 \pm 63.93$ and $283.67 \pm 46.78 \mathrm{~min}$, respectively. According to independent sample $t$-test, no significant difference was seen between the two groups $(P=0.077)$. Moreover, the duration of surgery was almost similar between the two groups $(P=0.165)$. (Table 3)

\section{Postoperative Adverse Effects}

The incidence of complications such as hypotension, bradycardia, respiratory depression, shivering, as well

Table 3 Duration of Analgesia, Motor Block and Surgery in Two Groups

\begin{tabular}{|l|l|l|l|}
\hline Parameters & $\begin{array}{l}\text { Group B-D } \\
\text { (n=55) }\end{array}$ & $\begin{array}{l}\text { Group B-F } \\
\text { (n=55) }\end{array}$ & $\begin{array}{l}\boldsymbol{P} \text { - } \\
\text { value }\end{array}$ \\
\hline Duration of analgesia (min) & $428.64 \pm 73.39$ & $273.18 \pm 61.91$ & $<0.00 I^{*}$ \\
Duration of motor block (min) & $\begin{array}{l}264.86 \pm 63.93 \\
283.67 \pm 46.78\end{array}$ & $\begin{array}{l}0.077 \\
51.36 \pm 8.58\end{array}$ & 0.165 \\
Duration of surgery (min) & $51.18 \pm 15.39$ & $51.36 \pm 8$ \\
\hline
\end{tabular}

Notes: Values are presented as mean \pm SD. Use of independent sample $t$-test. $\mathrm{P}<0.05$ was considered statistically significant. *Significant difference between two groups according to independent sample $t$-test.

Abbreviations: Group B-D, bupivacaine+dexmedetomidine; Group B-F, bupivacaine+fentanyl. as nausea and vomiting was recorded in two groups (Table 4).

\section{Apgar Score Evaluation}

The first minute Apgar score in the B-D and B-F groups was $8.85 \pm 0.62$ and $8.78 \pm 0.96$, respectively $(P=0.782)$. Moreover, the fifth minute Apgar score of the B-D and B-F groups was $9.89 \pm 0.50$ and $9.85 \pm 0.68$, respectively $(P=0.982)$. The results of Apgar scores showed no significant difference at the time points of one and five minutes.

\section{Discussion}

In the present study intrathecal administration of dexmedetomidine and fentanyl combined with bupivacaine compared in women undergoing cesarean section. The results showed that adding $5 \mu \mathrm{g}$ of dexmedetomidine to bupivacaine has a better effect on postoperative pain management compared to $25 \mu \mathrm{g}$ fentanyl.

Today, intrathecal administration of Dex has attracted considerable attention during spinal anesthesia with the aim of increasing the duration of analgesia and decreasing postoperative pain. Many studies have addressed the administration of different doses of intrathecal Dex $(3 \mu \mathrm{g}, 5 \mu \mathrm{g}, 10 \mu \mathrm{g}, 15$ $\mu \mathrm{g})$ as an adjuvant to local anesthetics. ${ }^{16-19}$ It seems that Dex induces the activation of $\alpha_{2}$-agonist receptors in the spinal cord, which leads to a decrease in the transmission of nociceptive signals such as substance P. It has also been revealed that its analgesic effects after the surgery are due to the inhibition of the intracellular potassium transport activities. ${ }^{20}$

As Dex binds to $\alpha_{2}$ receptors in the locus coeruleus, reduces norepinephrine release, and inhibits sympathetic activity, it can cause hypotension and bradycardia. Hence, evaluation of hemodynamic changes in patients was of great importance in this study. There was no significant difference between the B-D and B-F groups in terms of SBP, DBP, HR, MAP, and SpO2 at most of the studied

Table 4 Comparison of Complications in Two Groups

\begin{tabular}{|l|l|l|l|l|l|}
\hline \multirow{2}{*}{ Characteristics } & \multicolumn{2}{l|}{$\begin{array}{l}\text { Group B-D } \\
\text { (n=55) }\end{array}$} & \multicolumn{2}{l|}{$\begin{array}{l}\text { Group B-F } \\
\text { (n=55) }\end{array}$} & \multirow{2}{*}{-value } \\
\cline { 2 - 6 } & Number & $\%$ & Number & $\%$ & \\
\hline Hypotension & 30 & 54.5 & 37 & 67.3 & 0.171 \\
Bradycardia & 8 & 14.5 & 5 & 9.1 & 0.376 \\
Respiratory depression & 1 & 1.8 & 1 & 1.8 & 1.000 \\
Shivering & 4 & 7.3 & 9 & 16.4 & 0.140 \\
Nausea/vomiting & 3 & 5.5 & 5 & 9.1 & 0.716 \\
\hline
\end{tabular}

Notes: Values are presented as number and percentage. Use of chi-squared test. $P<0.05$ was considered statistically significant. Abbreviations: Group B-D, bupivacaine+dexmedetomidine; Group B-F, bupivacaine+fentanyl. 
times, which is in accordance with the results of the previous studies. ${ }^{3,16,18,21}$ Moreover, the findings of this study revealed the usage of ephedrine and atropine had no significant difference between the two groups, which were similar to the other studies. ${ }^{3,22,23}$ However, Contractor et al showed that the probability of MAP and HR decrease was higher in the Dex group compared to the control group. ${ }^{8}$ It is worth mentioning that in the mentioned study, the patients received intravenous Dex infusion under spinal anesthesia. The study by Shukla et al also showed that although MAP was similar between groups, bradycardia was more likely in the Dex group. ${ }^{21}$ However, the mentioned study also examined Dex and $\mathrm{MgSo}_{4}$ as an adjunct to spinal anesthesia.

The results of this study indicated that the onset of block in the B-D group was faster than in the B-F group. There was no significant difference between the two groups in sensory block level, which was consistent with the findings of other studies. ${ }^{2,23}$

Considering the pain intensity based on VAS score, the results showed that pain intensity was less in the B-D group during recovery room period (T0). However, at $\mathrm{T} 1, \mathrm{~T} 3$ and $\mathrm{T} 6$ in the postoperative period, no significant difference was observed between the groups. The mentioned observation may be attributed to the effects of Dex on the inhibition of pain receptors at the spinal cord that decreased c-fiber translocation and hyperpolarization of dorsal horn neurons. ${ }^{22}$ This finding was in agreement with the results of studies conducted by Gupta et al and Mahendru et al ${ }^{18,24}$ and was consistent with the study by Sun et al, just in the first hour while at two and four hours after the surgery, patients in the fentanyl group experienced less pain. ${ }^{2}$

Moreover, compared with the B-F group, the duration of analgesia in the B-D group was significantly longer. The mentioned findings were entirely consistent with the results of studies by Jain et al and Gupta et al. ${ }^{3,18}$ In another fascinating study, Shukla et al compared the effect of adding Dex and $\mathrm{MgSO}_{4}$ to intrathecal bupivacaine and found that the onset of block was faster in the Dex group and duration of analgesia also was significantly longer in Dex group. ${ }^{21}$ The results of the present study were in contrast with those of the Khalifa et al study; however, it is worth noting that the mentioned study used sufentanyl $0.1 \mu \mathrm{g}$ instead of fentanyl and did not find any significant difference between the sufentanyl and Dex groups regarding the duration of postoperative analgesia. Moreover, both groups in the mentioned study had a similar analgesic course. ${ }^{25}$
The results of this study indicated that the duration of motor block and the length of surgery were almost identical between the two groups. The findings of this study were in line and in contrast with the findings of Sun et al study in terms of the length of surgery and the duration of motor block, respectively ${ }^{2}$ which Dex group in the mentioned study had a longer duration of block, that may be ascribed to the higher dose of Dex $(10 \mu \mathrm{g})$ in the mentioned study, whereas the present study used $5 \mu \mathrm{g}$ Dex.

Regarding other complications such as shivering, nausea and vomiting, and respiratory depression, there were no differences between these two groups in the present study, which was in agreement with the results of other studies. ${ }^{12,24}$ However, Sun et al indicated that shivering, as well as nausea and vomiting, was most commonly observed in the fentanyl group. ${ }^{2}$

In the evaluation of the neonatal outcome, Apgar scores were compared between the two groups at one and five minutes after the birth that were almost identical between the two groups. The mentioned finding was in line with the results of other studies ${ }^{2,3}$ although Jain et $\mathrm{al}^{3}$ evaluated neonatal outcome with fetal heart rate.

\section{Conclusions}

Based on the results of this study, it can be stated that intrathecal administration of Dex is superior to intrathecal fentanyl in cesarean section; it not only caused faster block but also led to more extended postoperative analgesia and less intense pain. Moreover, Dex provided stable hemodynamic conditions. Hence, addition of $5 \mu \mathrm{g}$ of Dex to bupivacaine can be considered as an adjunct to local anesthetic during cesarean section under spinal anesthesia.

\section{Data Sharing Statement}

The data that support the findings of this study are accessible from the corresponding author upon reasonable request.

\section{Acknowledgments}

We would like to thank Hormozgan anesthesiology, critical care, and pain management research center staff, Farnoosh Tofighi, Nina Heydari and Masoumeh Mahmoodi for writing assistance, Esmaeel Alimolaee who contributed to the editing of the manuscript.

\section{Author Contributions}

All authors made substantial contributions to conception and design, acquisition of data, or analysis and interpretation of data; except MS who was involved in data acquisition. All 
authors, including MS, took part in drafting the article or revising it critically; agreed to submit to the current journal; gave final approval of the version to be published; and agree to be accountable for all aspects of the work.

\section{Funding}

No funding was received.

\section{Disclosure}

The authors report no conflicts of interest in this work.

\section{References}

1. Khosravi F, Alishahi M, Khanchemehr Y, Jarineshin H. A comparison between the effects of preloading with Ringer's solution and voluven on hemodynamic changes in patients undergoing elective cesarean section under spinal anesthesia. Med Arch. 2019;73(1):44. doi:10.5455/medarh.2019.73.44-48

2. Sun Y, Xu Y, Wang G-N. Comparative evaluation of intrathecal bupivacaine alone, bupivacaine-fentanyl, and bupivacaine-dexmedetomidine in caesarean section. Drug Res. 2015;65(09):468-472.

3. Jain N, Mathur PR, Soni P, Patodi V, Sethi SK, Mathur V. A comparative clinical study of intrathecal bupivacaine $2.5 \mathrm{mg}$ with dexmedetomidine $5 \mu \mathrm{g}$ versus intrathecal bupivacaine $2.5 \mathrm{mg}$ with fentanyl $25 \mu \mathrm{g}$ on the duration of labor analgesia using combined spinal epidural technique. J Obstet Anaesth Crit Care. 2019;9(1):2429. doi:10.4103/joacc.JOACC_21_18

4. Rahimzadeh P, Faiz SHR, Imani F, Derakhshan P, Amniati S. Comparative addition of Dexmedetomidine and fentanyl to intrathecal bupivacaine in orthopedic procedure in lower limbs. $B M C$ Anesthesiol. 2018;18(1):62. doi:10.1186/s12871-018-0531-7

5. Dahl JB, Jeppesen IS, Jorgensen H, Wetterslev J, Moiniche S. Intraoperative and postoperative analgesic efficacy and adverse effects of intrathecal opioids in patients undergoing cesarean section with spinal anesthesia: a qualitative and quantitative systematic review of randomized controlled trials. Anesthesiol J Am Soc Anesthesiol. 1999;91(6):1919-1927.

6. Jarineshin H, Fekrat F, Kermanshah AK. Treatment of postoperative pain in pediatric operations: comparing the efficiency of bupivacaine, bupivacaine-dexmedetomidine and bupivacaine-fentanyl for caudal block. Anesthesiol Pain Med. 2016;6(5). doi:10.5812/aapm.39495

7. Belzarena SD. Clinical effects of intrathecally administered fentanyl in patients undergoing cesarean section. Anesth Analg. 1992;74 (5):653-657. doi:10.1213/00000539-199205000-00006

8. Contractor HU, Gajjar VA, Shah VA. Evaluating effect of intravenous Dexmedetomidine on hyperbaric bupivacaine spinal anesthesia. Anaesth Pain Intensive Care. 2016;20(4):398-403.

9. Bajwa SJS, Bajwa SK, Kaur J, et al. Dexmedetomidine and clonidine in epidural anaesthesia: a comparative evaluation. Indian J Anaesth. 2011;55(2):116. doi:10.4103/0019-5049.79883

10. Niu X-Y, Ding X-B, Guo T, Chen M-H, Fu S-K, Li Q. Effects of intravenous and intrathecal dexmedetomidine in spinal anesthesia: a meta-analysis. CNS Neurosci Ther. 2013;19(11):897-904. doi:10.11 $11 / \mathrm{cns} .12172$

11. Gómez-Vázquez ME, Hernández-Salazar E, Hernández-Jiménez A, Pérez-Sánchez A, Zepeda-López VA, Salazar-Páramo M. Clinical analgesic efficacy and side effects of dexmedetomidine in the early postoperative period after arthroscopic knee surgery. $J$ Clin Anesth. 2007;19(8):576-582. doi:10.1016/j.jclinane.2007.06.013
12. Gupta R, Verma R, Bogra J, Kohli M, Raman R, Kushwaha JK. A comparative study of intrathecal Dexmedetomidine and fentanyl as adjuvants to bupivacaine. J Anaesthesiol Clin Pharmacol. 2011;27 (3):339. doi:10.4103/0970-9185.83678

13. Jain D, Khan RM, Kumar D, Kumar N. Perioperative effect of epidural Dexmedetomidine with intrathecal bupivacaine on haemodynamic parameters and quality of analgesia. South Afr J Anaesth Analg. 2012;18(2):105-109. doi:10.1080/22201173.2012.10872835

14. Bhure A, Jagtap N. A comparison of intrathecal Dexmedetomidine and fentanyl as an adjuvant to isobaric levobupivacaine for lower limb orthopaedic surgery. Indian J Clin Anaesth. 2019;6(1):89-96. doi:10.18231/2394-4994.2019.0017

15. Qi X, Chen D, Li G, et al. Comparison of intrathecal Dexmedetomidine with morphine as adjuvants in cesarean sections. Biol Pharm Bull. 2016;b16-00145.

16. Jarineshin H, Baghaei AA, Fekrat F, et al. Comparison of two different doses of Dexmedetomidine in attenuating cardiovascular responses during laryngoscopy and endotracheal intubation: a double blind, randomized, clinical trial study. $J$ Med Life. 2015;8(Spec Iss 4):45.

17. Nayagam HA, Singh NR, Singh HS. A prospective randomised double blind study of intrathecal fentanyl and Dexmedetomidine added to low dose bupivacaine for spinal anesthesia for lower abdominal surgeries. Indian J Anaesth. 2014;58(4):430. doi:10.4103/00195049.138979

18. Gupta R, Bogra J, Verma R, Kohli M, Kushwaha JK, Kumar S. Dexmedetomidine as an intrathecal adjuvant for postoperative analgesia. Indian J Anaesth. 2011;55(4):347. doi:10.4103/00195049.84841

19. Khosravi F, Sadeghi N, Jarineshin H. The effect of Dexmedetomidine on spinal anesthesia quality and hemodynamic changes in patients undergoing inguinal hernia repair surgery: intravenous versus intrathecal. Eur J Clin Pharmacol. 2020;76(7):923-928. doi: doi:10.1007/s00228-020-02870-8

20. Arain SR, Ruehlow RM, Uhrich TD, Ebert TJ. The efficacy of Dexmedetomidine versus morphine for postoperative analgesia after major inpatient surgery. Anesth Analg. 2004;98(1):153-158. doi:10.1213/01.ANE.0000093225.39866.75

21. Shukla D, Verma A, Agarwal A, Pandey HD, Tyagi C. Comparative study of intrathecal Dexmedetomidine with intrathecal magnesium sulfate used as adjuvants to bupivacaine. J Anaesthesiol Clin Pharmacol. 2011;27(4):495. doi:10.4103/0970-9185.86594

22. Suthar O, Sethi P, Sharma UD. Comparison of Dexmedetomidine and clonidine as an adjuvant to intrathecal bupivacaine in lower limb surgery: a randomised, double-blind, placebo controlled trial. Anaesth Pain Intensive Care. 2019;147-152.

23. Shahi V, Verma AK, Agarwal A, Singh CS. A comparative study of magnesium sulfate vs Dexmedetomidine as an adjunct to epidural bupivacaine. J Anaesthesiol Clin Pharmacol. 2014;30(4):538. doi:10.4103/0970-9185.142852

24. Mahendru V, Tewari A, Katyal S, Grewal A, Singh MR, Katyal R. A comparison of intrathecal Dexmedetomidine, clonidine, and fentanyl as adjuvants to hyperbaric bupivacaine for lower limb surgery: a double blind controlled study. J Anaesthesiol Clin Pharmacol. 2013;29(4):496. doi:10.4103/0970-9185.119151

25. Khalifa IF. A comparative study of adding intrathecal Dexmedetomidine versus sufentanil to heavy bupivacaine for postoperative analgesia in patients undergoing inguinal hernia repair. Benha Med J. 2009;26:3-11. 


\section{Publish your work in this journal}

The Journal of Pain Research is an international, peer reviewed, open access, online journal that welcomes laboratory and clinical findings in the fields of pain research and the prevention and management of pain. Original research, reviews, symposium reports, hypothesis formation and commentaries are all considered for publication. The manuscript management system is completely online and includes a very quick and fair peer-review system, which is all easy to use. Visit http:// www.dovepress.com/testimonials.php to read real quotes from published authors. 